\title{
Detection of Automotive Emissions Status using Fuzzy Inference System
}

\author{
Mohammad Al Zubi, Ayman M. Mansour ${ }^{2}$ \\ ${ }^{I}$ (Mechanical Engineering Department, College of Engineering/Tafila Technical University, Jordan) \\ ${ }^{2}$ (Electrical Engineering Department, College of Engineering/ Tafila Technical University, Jordan)
}

\begin{abstract}
The adoption of a fuzzy control system to determine the emission values of $\mathrm{CO}, \mathrm{CO}_{2}, \mathrm{NO}_{x}, \mathrm{HC}$ and $\mathrm{O}_{2}$ from an SI engine is studied depending upon the air fuel ratio $(A / F)$, as known that the emission values are highly related to $\mathrm{A} / \mathrm{F}$ ratio, the target of the combustion process in the internal combustion engine is to be as close to stoichiometric as possible, however the driving conditions play a significant role in the value of this ratio. Fuzzy logic is used to represent, interpret, and compute vague and/or subjective information of automotive emissions. Fuzzy logic approach uses human language and thinking strategies in a way for decision making based on domain expert knowledge, and rules of thumb even for systems without any mathematical model.
\end{abstract}

Keywords: Air fuel ratio, Emissions, Fuzzy logic, Detection, Mamdani.

\section{Introduction}

The study of the SI engine's emissions is an important issue to the automotive manufacturers as these emissions affect the environment from one side and because the limits of these emissions is controlled according to the regulations set by many agencies like EPA [1]. Fuel consumption and emission models using vehicle speed and acceleration levels as input variables were studied in [2], the models were found to produce vehicle emissions that were consistent with the ORNL data. The use of 3 way catalytic converter which promotes the reduction of nitrogen oxides and the oxidation of carbon monoxide and hydrocarbons in gasoline-fueled vehicles was discussed in [3]. Controlling the air-fuel ratio with an oxygen sensor used with a three-way catalyst showed a significant reduction of $\mathrm{CO}, \mathrm{NO}_{x}$, emissions [4]. The effect of the change in driver's behavior and the variability associated with individual driving styles like duration of acceleration events showed significant differences in measured emissions [5]. The effect of the air-fuel equivalence ratio and ethanol content in gasoline showed that $\mathrm{CO}$ and $\mathrm{HC}$ emission content were reduced with an increase of ethanol content, this was due to oxygen enrichment coming from ethanol [6]. It was noticed in [7] that $\mathrm{NO}_{\mathrm{x}}$ emission was closely related to the equivalence ratio, such that $\mathrm{NO}_{\mathrm{x}}$ emission reaches a maximum near the stoichiometric condition and $\mathrm{NO}_{\mathrm{x}}$ emission depends on the engine operating condition rather than the ethanol content in gasoline. Finally, The cold starting emission levels were studied in [8] using ethanol blended with gasoline, the study showed that for best cold-start emissions the ethanol content in gasoline should be at least 20 percent but no greater than 30 per cent.

Fuzzy logic [9] is a well-established methodology that is effective for systematic handling of deterministic uncertainty and subjective information. Fuzzy logic is useful especially when a mathematical model of a system is not available and rules of the thumb from domain experts are available [10]. It has been successfully used to solve challenging industrial and medical problems in practice, some of which are very difficult to solve without it. Using Fuzzy rule based approach in this paper is dependent upon air fuel ratio as an input to the system to well define the values of the five major engine emissions. This system makes it easy to know exactly the values at any operating condition which can be used in the future with the ECM to reduce emissions.

In this paper the reasoning is implemented using MATLAB Fuzzy toolbox. The detecting task of the proposed system is performed by the Inference Engine that evaluates all the rules in a knowledge Base and combines the weighted consequents of all relevant rules into a single output fuzzy set that shows the status of an emission. That set is then defuzzified to produce a crisp emission status value. The automotive emission status detector is experience-based as experience plays a key role in the design of the Detector. 


\section{Automotive Emission Concept}

In the United States, emissions standards are managed by the Environmental Protection Agency (EPA) as well as some U.S. state Governments [9]. The exhaust emissions from internal-combustion engines account for a major portion of air pollution. It is known that the content and concentrations of the exhaust emissions depend on various parameters like engine design parameters, operational parameters, exhaust gas after treatment, fuel and oil type[ref]. The three main pollutants which are subject to exhaust emission legislation are carbon monoxide (CO), unburned hydrocarbons ( $\mathrm{HC}$ ) and nitrogen oxides ( $\mathrm{NO} x$ ). a typical graph for automotive emissions is shown below [11].

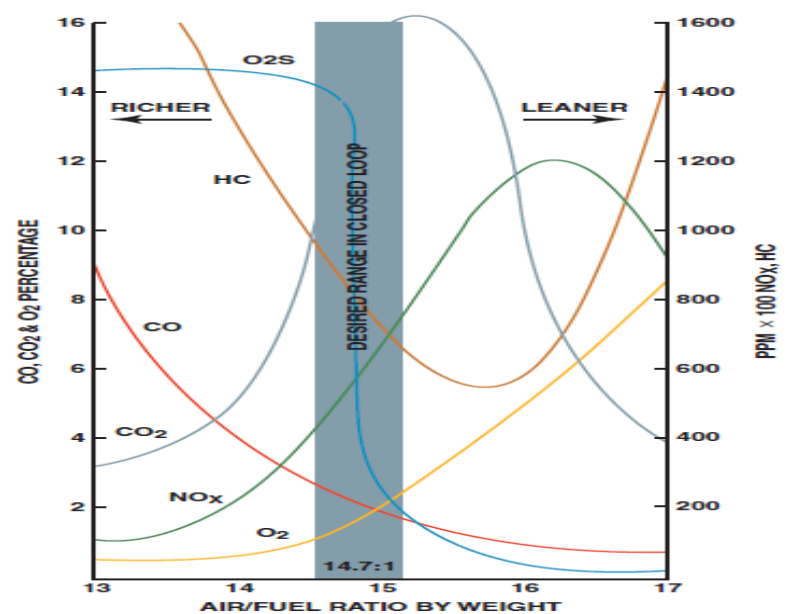

Fig.1. Emission values as a function of Air/Fuel Ratio [11]

The most common gases to be analyzed and their significance are:

HYDROCARBONS (HC): it represents the unburned fuel (gasoline)in the combustion process, and are measured in parts per million (ppm). If the engine is working fine, the chemical reaction inside the combustion chamber should oxidize the majority of the fuel, the rest of the HC should appear in the exhaust stream with a value of $50 \mathrm{ppm}$ or less. A defective ignition system will cause these emissions to exceed the acceptable range.

CARBON MONOXIDE (CO) is a poisonous gas, so when combined with oxygen to form $\mathrm{CO} 2$ in the lungs 1 , it will cause shortage of oxygen arrives to the. An efficient engine should have CO levels to be less than $0.5 \%$, however high levels of CO can be caused by clogged air filter of excessive fuel pressure which will make a rich $\mathrm{A} / \mathrm{F}$ ratio.

CARBON DIOXIDE $\left(\mathrm{CO}_{2}\right)$ is a good indicator of the combustion efficiency in the engine. An acceptable level of CO 2 is between $12 \%$ and 15\%. The higher the number the better the engine operating conditions. If the $\mathrm{CO} 2$ level is low, the mixture may be far away from stoichiometric (too rich or too lean).

OXYGEN $\left(\mathrm{O}_{2}\right)$ should be consumed in the combustion process to oxidize the fuel (hydrocarbon) during the combustion process. Levels of $\mathrm{O}_{2}$ should be very low (about $0.5 \%$ ). High levels of $\mathrm{O}_{2}$, especially at idle, could be due to an exhaust system leak. To reduce $\mathrm{CO}$ emissions in the fuel alcohol is blended with the gasoline, but high levels of oxygen will appear in the exhaust emissions.

OXIDES OF NITROGEN $\left(\mathrm{NO}_{\mathrm{x}}\right)$ is a colorless, tasteless, and odorless gas when it leaves the engine, it is responsible about photochemical smog formation as soon as it reaches the atmosphere and mixes with more oxygen, and nitrogen oxides $\left(\mathrm{NO}_{2}\right)$ are formed. $\mathrm{NO}_{2}$ is reddish-brown and has an acid smell. $\mathrm{NO}_{\mathrm{x}}$ referred to $\mathrm{NO}, \mathrm{NO}_{2}$, where $\mathrm{x}$ represents any number of oxygen atoms. NOx is the product of high temperature combustion, so the exhaust gas recirculation (EGR) system is used to control it. A reading of $1000 \mathrm{ppm}$ under load is acceptable for NOx.

\section{Design And Implementation}

Fuzzy logic is used here to represent, interpret, and compute vague and subjective information. Fuzzy reasoning provides an inference procedure that derives conclusions from known facts and a set of fuzzy if-then rules [9]. The structure of the proposed system is is indicated in Figure 2. The Structure includes four components: Fuzzifier, Inference Engine, Knowledge Base, and Defuzzifier. The Fuzzifier translates Air Fuel crisp Ratio inputs into fuzzy values. The Inference Engine is the part that controls the process of deriving conclusions. It applies a fuzzy reasoning mechanism to obtain a fuzzy output using rules and the fuzzy values which represents the automotive emissions. The Fuzzy Inference System follows Mamdani fuzzy model. The Knowledge Base contains a set of fuzzy IF-THEN rules and a set of membership functions of fuzzy sets. The 
Defuzzifier coverts the fuzzy output into a crisp value that best represents the out fuzzy set. The Defuzzifier uses the center of gravity scheme. The implication methods used in the proposed system are min (minimum), which truncates the individual output fuzzy sets, and max (maximum), which scales the resulted output fuzzy sets. The input to the implication process is a single number given by antecedent.

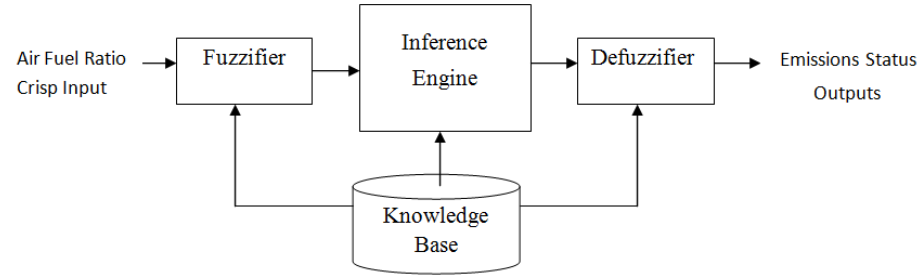

Fig.2. Block Diagram of the proposed Fuzzy system

The input and output variables will be defined in order to be used by the Fuzzy Inference Engine, and each variable is fuzzified by input fuzzy sets. The fuzzy sets used in fuzzifying the Input and Output variables are shown in TABLE 1.Triangular and bell fuzzy sets are specified by three parameters $a, b$ and $c$ while the gaussian fuzzy set is specified by two parameters $a$ and $b$ and trapezoidal fuzzy set is specified by four parameters a, b, c, and d.

Table 1.Definitions of Fuzzy Sets used in the proposed system

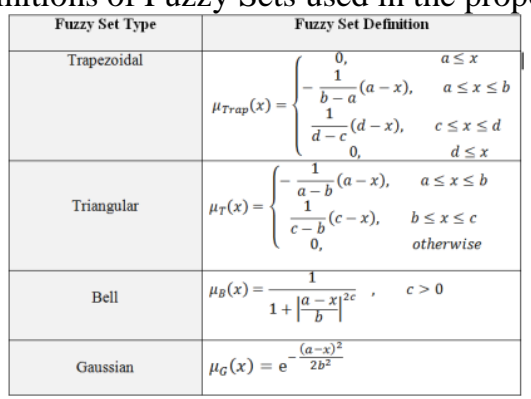

Figure 3 indicates one input; Air Fuel Ratio (kg Air/kg Fuel), which has three membership functions and the figure indicates five outputs as well; those are Carbon Monoxide Emission (CO), Carbon Dioxide Emission (CO2) , Oxygen Emission (O2), Hydrocarbon (HC), and Nitrogen Oxides (NOx), those have $(2,3,2,2,3)$ membership functions respectively .

The corresponding membership function of the input variable and output variables are shown in Figure 4, Figure 5, Figure 6, Figure 7, Figure 8 and Figure 9 respectively. For each linguistic variable a combination of membership functions are defined. Sufficient overlapping degree between the membership functions is ensured to obtain a smooth output relationship.

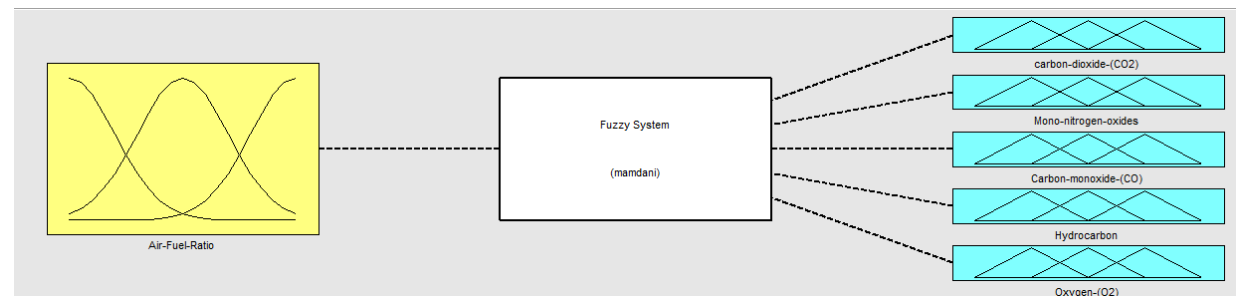

Fig.3. Fuzzy model for Detection of Automotive Emission status

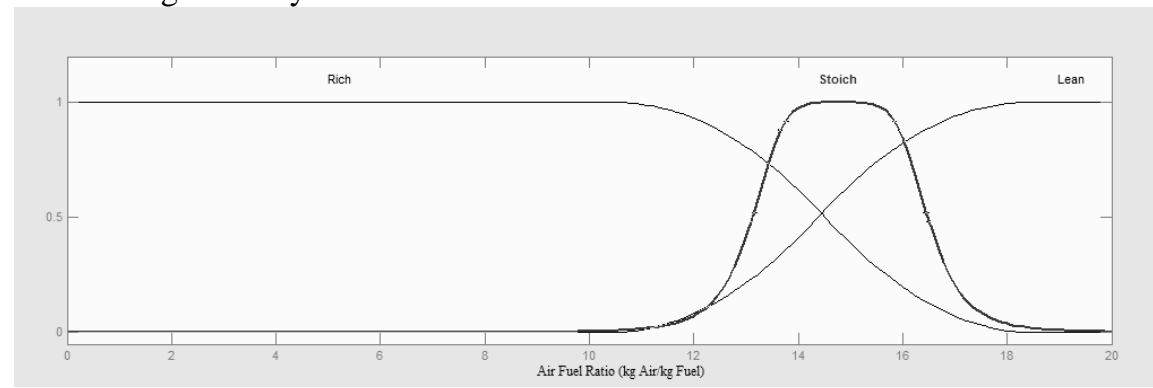

Fig.4. Fuzzy sets for Air Fuel Ratio 


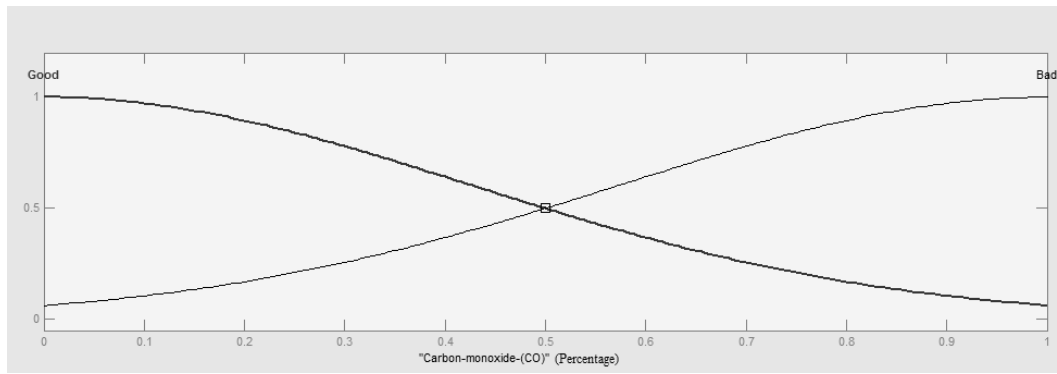

Fig.5. Membership functions for Carbon Monoxide Emission (CO) linguistic variable

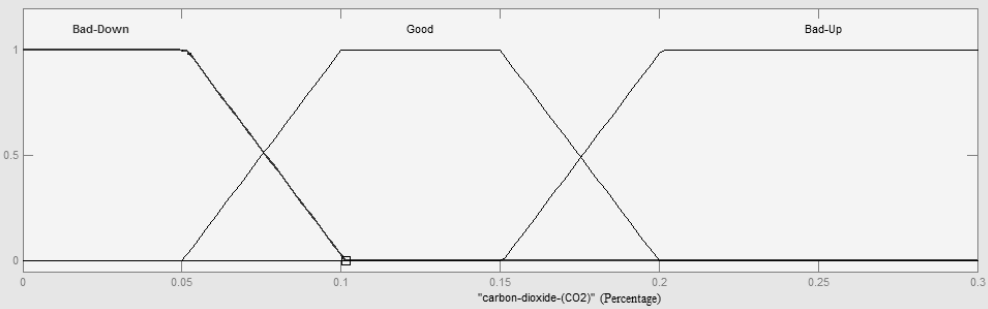

Fig.6. Membership functions for Carbon Dioxide Emission $(\mathrm{CO} 2)$ linguistic variable

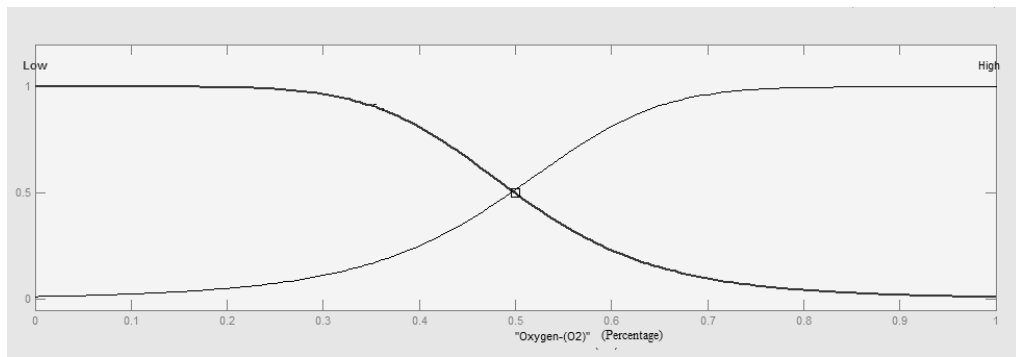

Fig.7. Membership functions for Oxygen Emission (O2) linguistic variable

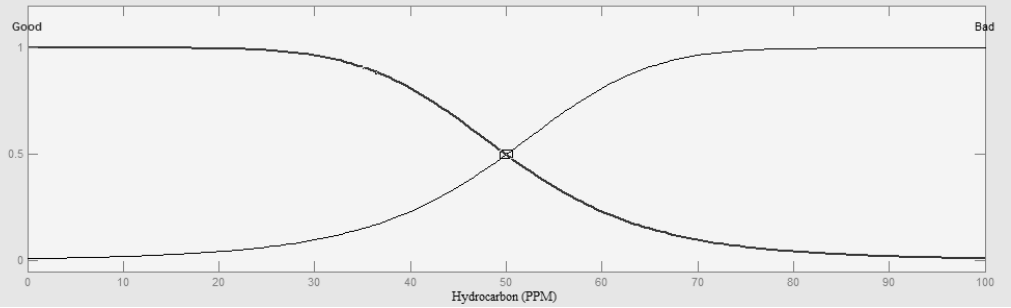

Fig.8. Membership functions for Hydrocarbon Emission variable

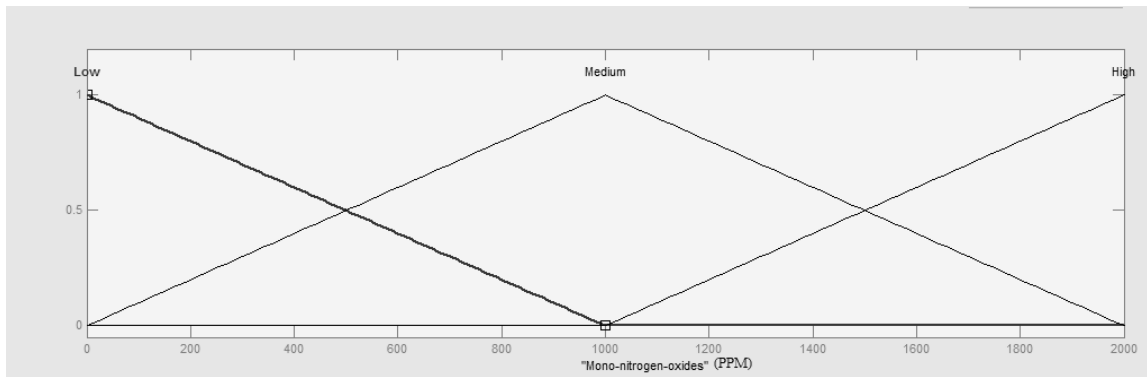

Fig.9. Membership functions for Mono Nitrogen Oxide Emission linguistic variable

The developed fuzzy system has a total of 17 rules in the fuzzy Knowledge Base. The rules used in the fuzzy system were formed as follows:

1. If Air Fuel Ration is Stoich, then Carbon dioxide is Good.

2. If Air Fuel Ration is Stoich, then Mono nitrogen oxide is Medium.

3. If Air Fuel Ration is Stoich, then Carbon monoxide is Good.

4. If Air Fuel Ration is Stoich, then Hydrocarbon is Good .

5. If Air Fuel Ration is Stoich, then Oxygen is Low. 
6. If Air Fuel Ration is Lean, then Carbon dioxide is Bad-Down.

7. If Air Fuel Ration is Lean, then Mono nitrogen oxide is High.

8. If Air Fuel Ration is Lean, then Carbon monoxide is Good.

9. If Air Fuel Ration is Lean, then Hydrocarbon is Good .

10. If Air Fuel Ration is Lean, then Oxygen is High.

11. If Air Fuel Ration is Lean, then Carbon dioxide is Bad-UP.

12. If Air Fuel Ration is Rich, then Carbon dioxide is Good.

13. If Air Fuel Ration is Rich, then Mono nitrogen oxide is Low.

14. If Air Fuel Ration is Rich, then Carbon monoxide is Bad.

15. If Air Fuel Ration is Rich, then Hydrocarbon is Bad .

16. If Air Fuel Ration is Rich, then Oxygen is Low.

17. If Air Fuel Ration is Rich, then Mono nitrogen oxide is Medium.

\section{Results}

The Mamdani fuzzy system is implemented using the Fuzzy logic toolbox. The rules are obtained from the knowledge of the experts and entered in the rule editor box. Figure 10, Figure 11, Figure 12, Figure13 and Figure 14 show the resulted surface viewer for the above mentioned system.

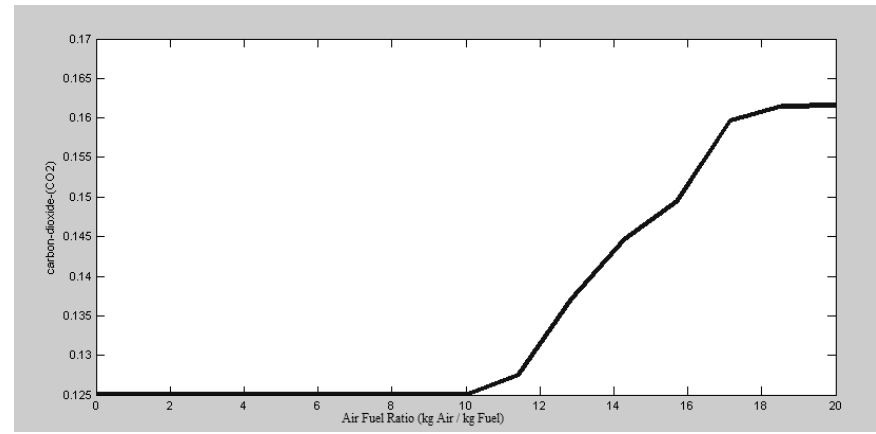

Fig.10. Surface Analysis between Air Fuel Ratio and Carbon Dioxide(CO2)

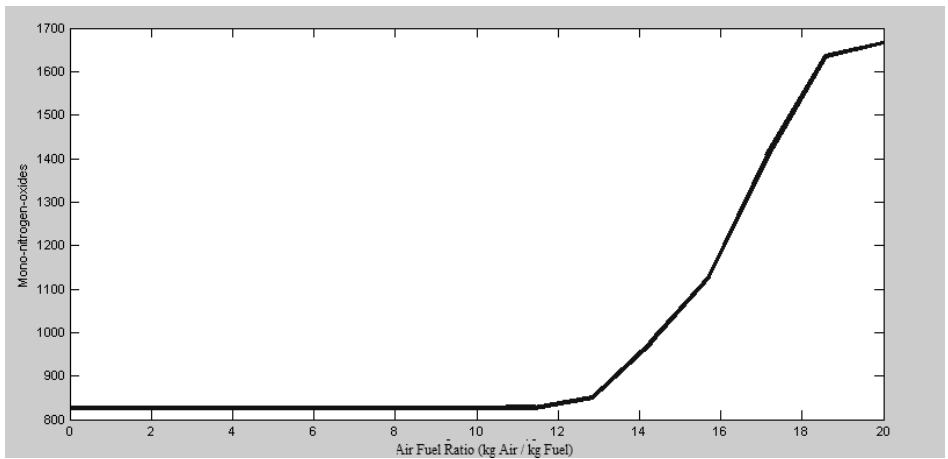

Fig.11. Surface Analysis between mixing Air Fuel Ratio and coolant Mono Nitrogen Oxides

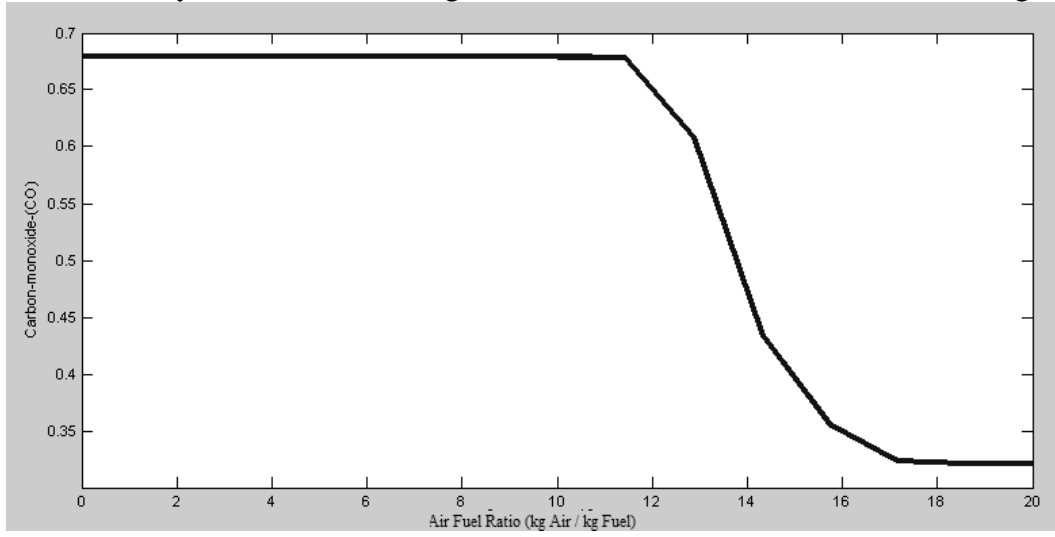

Fig.12. Surface Analysis between mixing Air Fuel Ratio and coolant Carbon monoxide (CO) 


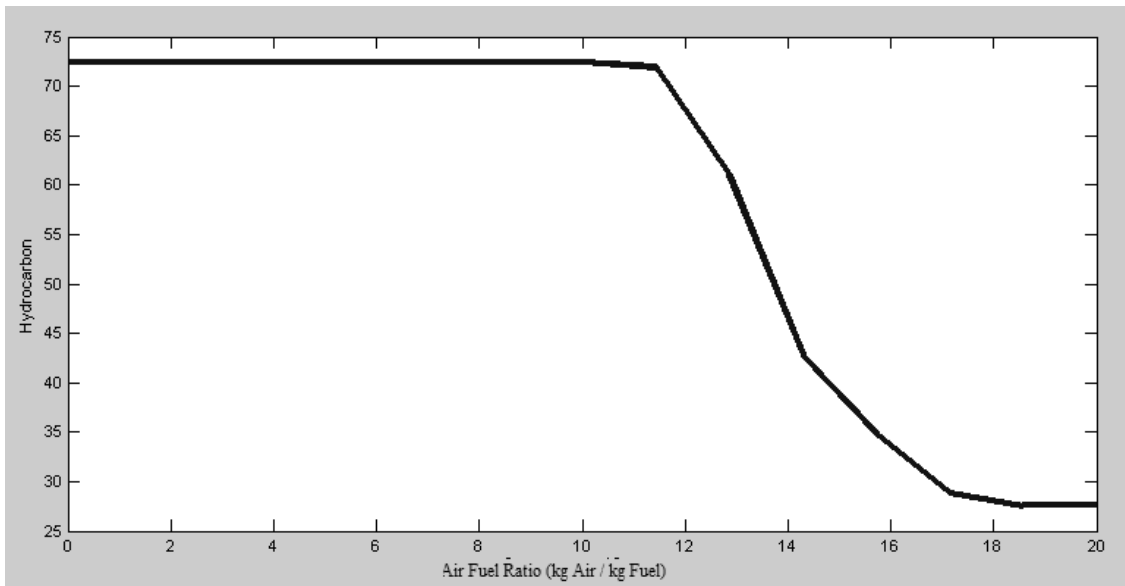

Fig.13. Surface Analysis between Air Fuel Ratio and coolant Hydrocabon

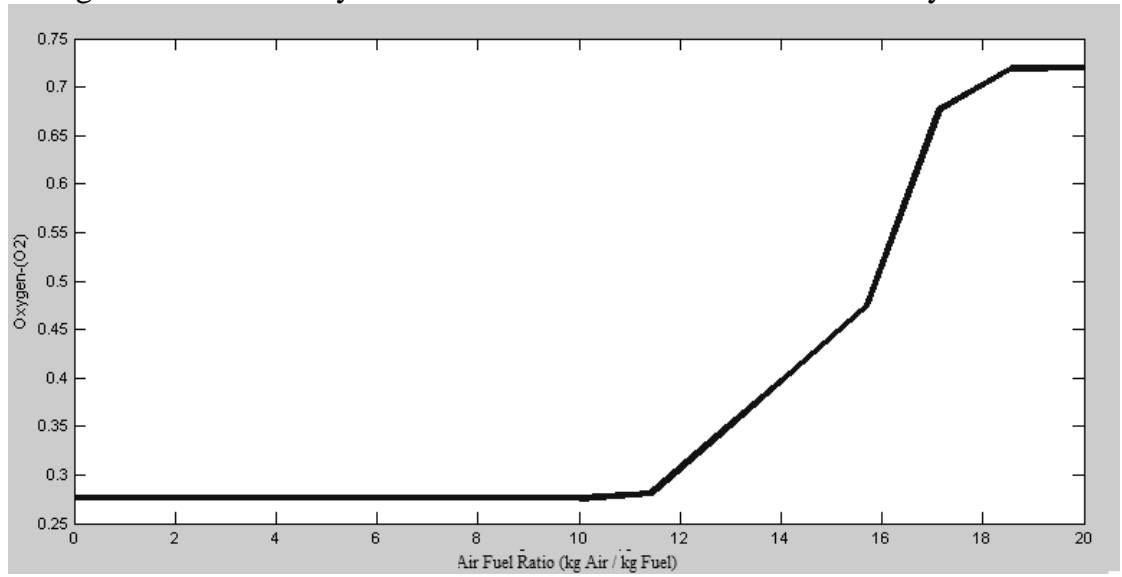

Fig.14. Surface Analysis between Air Fuel Ratio and Oxygen (O2)

A case study is given here to show the effect of the Air Fuel Ration on Automotive emissions. The input is feed in a rule viewer of MATLAB fuzzy inference system. Different output (Automotive emissions) are measured in response to changing input Air Fuel Ratio as shown in Figure 15.
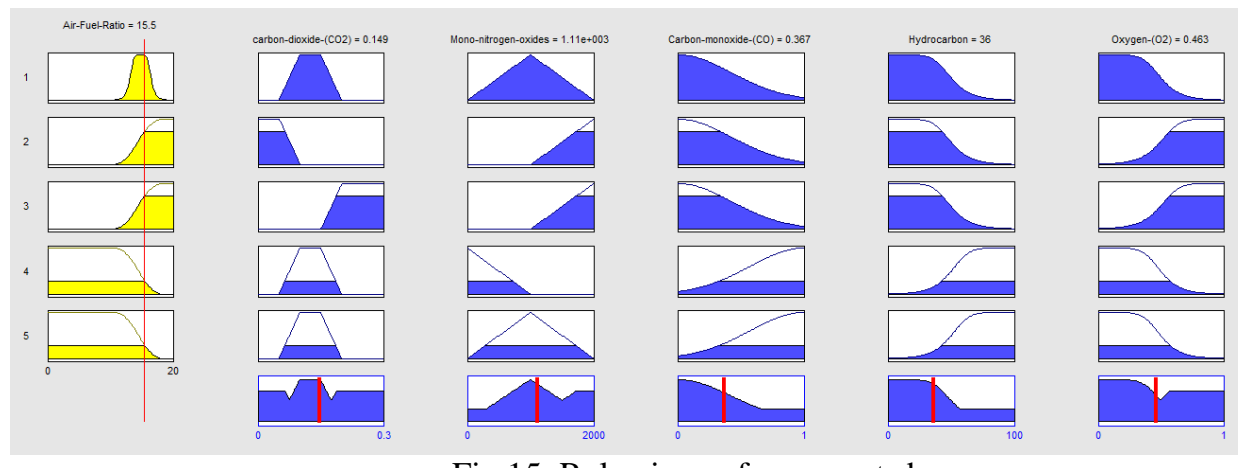

Fig.15. Rule viewer for a case study

As can be seen from the above results that hydrocarbon s emission are too high when the air fuel ratio is either lean or rich, while it is good at stoichiometric ratio . For carbon monoxide, it is too high at rich air fuel ratio, and it decreases as we go leaner. For oxygen emissions it is low at rich air fuel ratios and it increases as the mixture becomes richer. Nitrogen oxides increase as the air fuel ratio go to lean region, and this due to increased temperatures in the combustion chamber. Finally carbon monoxide is the best at stoichiometric (high values), while low values of this emission specie is low at either too rich or too lean condition.

\section{Conclusion}

In this paper, we have developed a fuzzy system that can give an accurate value of the any emission content at a specific air fuel ratio. The major emissions from an SI engine were investigated and very clear values of these emissions were shown depending on the air fuel ratio which is a vital parameter in this issue. Fuzzy system was used to exactly show these values at any air fuel ratio, this system relate the lean, rich and 
stoichiometric air fuel ratio to the status of any of these emissions; this system may be implemented with the Electronic Control Module (ECM) to better monitor the air fuel ratio for the best drivability conditions which leads to controlled emissions as well. The fuzzy system has been implemented using MATLAB toolbox.

\section{References}

[1] Environmental protection Agency. Emission Standards Reference Guide.USA, www.epa.gov.

[2] Kyoungho Ahn; Hesham Rakha, M.ASCE; Antonio Trani, M.ASCE; and Michel Van Aerde. Estimating Vehicle Fuel Consumption and Emissions based on Instantaneous Speed and Acceleration Levels. Journal of Transportation Engineering (J. Transp. Eng), Vol 128. 2002, 182-190.

[3] Kathleen C. Nitric Oxide Catalysis in Automotive Exhaust Systems . Taylor \& Francis Vol. 35, Iss. 4, Science and Engineering, 1993.

[4] J. Riegel, H. Neumann. Exhaust gas sensors for automotive emission control. Germany Solid State Ionics. 2002. 783-800

[5] Britt A Holmén, Debbie A Niemeier. Characterizing the effects of driver variability on real-world vehicle emissions. Transport and Environment,Volume 3, Issue 2, March 1998. 117-128.

[6] Chan-Wei Wua, Rong-Horng Chenb, Jen-YungPu a, Ta-Hui Lina. The influence of air-fuel ratio on engine performance and pollutant emission of an SI engine using ethanol-gasoline-blended fuels .Atmospheric Environment 38 (2004) 7093-7100.

[7] Wei-Dong Hsieha, Rong-Hong Chenb, Tsung-Lin Wub, Ta-Hui Lina Engine performance and pollutant emission of an SI engine using ethanol-gasoline blended fuels. Atmospheric Environment 36 (2002) 403-410.

[8] Rong-Horng Chen, Li-Bin Chiang, Chung-Nan Chen, Ta-Hui Lin . Cold-Start Emissions of an SI engine using ethanol gasoline blended fuel. Applied Thermal Engineering 31 (2011) 1463e1467

[9] Zadeh, Fuzzy sets*, Information and control, vol. 8, 1965, 338-353.

[10] Jyh-Shing Roger Jang, Chuen-Tsai Sun, Eiji Mizutani, Neuro-fuzzy and soft computing: a computational approach to learning and machine intelligence (Prentice-Hall, 1997).

[11] Halderman, Automotive Fuel and EmissionsControl Systems, $3^{\text {rd }}$ Edition, Printice Hall, 2011.

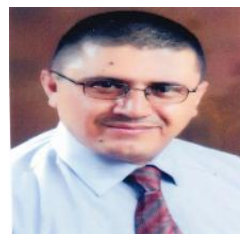

Dr. Mohammad A Al Zubi is currently an Assistant Professor in the Mechanical Engineering Department at Tafila Technical University, Jordan. He earned his PhD in Mechanical Engineering from Wayne State University, Detroit, Michigan, USA, in 2012. He also received the BSc degree in Mechanical Engineering in 1994 from Mu'tah University, Al Karak, Jordan and his MSc degrees in Industrial Automation Engineering in 2006 from Yarmouk University, Irbid, Jordan. His research experience and interests are in combustion emission control of SI engines, Automotive NVH, and renewable energy systems including wind and solar power. He is a Member of the American Society of Mechanical Engineers (ASME), Society of Automotive Engineers(SAE), and Jordan Engineers Association (JEA).

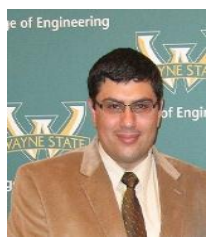

Dr. Ayman M Mansour received his Ph.D. degree in Electrical Engineering from Wayne State University in 2012. Dr. Mansour received his M.Sc degree in Electrical Engineering from University of Jordan, Jordan, in 2006 and his B.Sc degree in Electrical and Electronics Engineering from University of Sharjah, UAE, in 2004. He graduated top of his class in both Bachelor and Master. Currently, Dr. Mansour is an assistant professor in the Department of Electrical and computer Engineering, Tafila Technical University, Jordan. His areas of research include communication systems, multi-agent systems, fuzzy systems, data mining and intelligent systems. He conducted several researches in his area of interest. Dr. Mansour is a member of IEEE, Michigan Society of Professional Engineers, IEEE Honor Society (HKN), Tau Beta Pi Honor Society, Sigma Xi and Golden Key Honor Society. 